\title{
Bourgeois Behavior and Freeloading in the Colonial Orb Web Spider Parawixia bistriata (Araneae, Araneidae)
}

\author{
Tom Wenseleers, ${ }^{1}$ Jonathan P. Bacon, ${ }^{2, \star}$ Denise A. Alves, ${ }^{3}$ Margaret J. Couvillon, ${ }^{2}$ \\ Martin Kärcher, ${ }^{2}$ Fabio S. Nascimento, ${ }^{3}$ Paulo Nogueira-Neto, ${ }^{4}$ Marcia Ribeiro, ${ }^{5}$ \\ Elva J. H. Robinson, ${ }^{6}$ Adam Tofilski, ${ }^{7}$ and Francis L. W. Ratnieks ${ }^{2}$
}

1. Laboratory of Socioecology and Social Evolution, Zoological Institute, University of Leuven, 3000 Leuven, Belgium; 2. School of Life Sciences, University of Sussex, Falmer, Brighton BN1 9QG, United Kingdom; 3. Department of Biology, Faculty of Philosophy, Sciences, and Letters (FFCLRP), University of São Paulo, Avenue Bandeirantes, 3900, 14040901 Ribeirão Preto, Brazil; 4. Department of Ecology, Institute of Bioscience, University of São Paulo, Rua do Matão Travessa 14, 321, 05508-900 São Paulo, Brazil; 5. Embrapa Semiárido, BR 428 Km 152 zona rural C.P. 23, 56302-970 Petrolina, Brazil; 6. York Centre for Complex Systems Analysis, University of York, Heslington, York YO10 5DD, United Kingdom; 7. Department of Pomology and Apiculture, Agricultural University, 31-425

Krakow, Poland

Submitted July 16, 2012; Accepted February 5, 2013; Electronically published May 21, 2013

Online enhancement: appendix. Dryad data: http://dx.doi.org/10.5061/dryad.1205d.

AвSTRACT: Spiders of the tropical American colonial orb weaver Parawixia bistriata form a communal bivouac in daytime. At sunset, they leave the bivouac and construct individual, defended webs within a large, communally built scaffolding of permanent, thick silk lines between trees and bushes. Once spiders started building a web, they repelled other spiders walking on nearby scaffolding with a "bounce" behavior. In nearly all cases (93\%), this resulted in the intruder leaving without a fight, akin to the "bourgeois strategy," in which residents win and intruders retreat without escalated contests. However, a few spiders $(6.5 \%)$ did not build a web due to lack of available space. Webless spiders were less likely to leave when bounced (only $42 \%$ left) and instead attempted to "freeload," awaiting the capture of prey items in nearby webs. Our simple model shows that webless spiders should change their strategy from bourgeois to freeloading satellite as potential web sites become increasingly occupied.

Keywords: bourgeois strategy, freeloading, spiders, Parawixia bistriata.

\section{Introduction}

Most of the approximately 41,000 described species of spiders are solitary predators, and many can be cannibalistic. However, approximately 50 species from 12 families display highly cooperative social behavior (Quintero and Amat 1996; Avilés 1997; Uetz and Hieber 1997; Avilés et al. 2006) that typically involves communal building and defense of a web or silken framework and sometimes involves alloparental care and communal prey capture. The

\footnotetext{
* Corresponding author; e-mail: j.p.bacon@sussex.ac.uk.
}

Am. Nat. 2013. Vol. 182, pp. 120-129. (C) 2013 by The University of Chicago. 0003-0147/2013/18201-53980\$15.00. All rights reserved. DOI: $10.1086 / 670525$ most advanced social behavior is seen in some Theridiidae, such as Anelosimus eximius, which build large communal cobwebs with up to 50,000 spiders that can persist for many generations; this species appears to cooperate in all aspects of its behavior (Vollrath 1986).

Colonial behavior has also been recorded in several orb weaving spiders (Uetz and Hieber 1997). One of these, Parawixia (formally Eriophora) bistriata (Araneidae) occurs in semiarid habitats in Paraguay, Argentina, and Brazil (Sandoval 1987; Levi 1992) and seems to have been first recorded by Azara (1809) in Paraguay and by Darwin (1845) in Argentina. These spiders share a communal bivouac during the day, but at sunset each spider leaves the bivouac to construct its own orb web within a communally built scaffold of thick silk lines that link to nearby trees and bushes. Unusually for colonial orb weavers, $P$. bistriata also exhibits facultative, communal prey capture and feeding, with spiders feeding solitarily on small prey items, but with groups of 2-7 feeding together when prey are significantly larger than themselves (Fowler and Diehl 1978; Gobbi et al. 1979; Sandoval 1987; Fowler and Gobbi 1988a; Campon 2007).

Colonies are annual, with up to about 500 immature, synchronously developing spiders that are thought to be siblings originating from a single egg sac (Fowler and Diehl 1978; Fowler and Gobbi 1988b). Upon maturing, the males and females within a colony disperse, lay eggs away from the colony site, and die (Fowler and Diehl 1978; Gobbi et al. 1979). This is an atypical feature of social spiders; usually, colony members mate to produce offspring that re- 
main in the existing nest (Avilés et al 2006) so that the colony can persist for more than 1 year.

Although cooperative prey capture and prey sharing in P. bistriata has been previously studied (Fowler and Diehl 1978; Gobbi et al. 1979; Sandoval 1987; Fowler and Gobbi 1988a; Campon 2007), little is known about the construction of the individual webs and how this is achieved within the communal framework. The aim of this study was to investigate how the spiders resolve conflicts over the partitioning of web-building space during the establishment of their webs and whether conflicts continue after web building is completed. We show that, when a spider starts building a web, it uses a "bounce" behavior to repel other spiders that have not yet started building and are walking on scaffolding on which the builder's web is anchored. In nearly all cases, this results in the intruder walking farther down the scaffolding without a fight, apparently in an excellent example of the "bourgeois strategy" (Maynard Smith 1976, 1982; Mesterton-Gibbons 1992). We also show that, on any particular night, a small but significant percentage of spiders in most aggregations do not build a web. Instead, they remain on a piece of scaffolding silk on the edge of a resident's web. These webless spiders usually do not leave when bounced but remain as satellites and await the capture of large prey items in nearby webs, of which they frequently obtain a share. Using a simple mathematical model (see app. A), we show that the transition between bourgeois and satellite behavior comes about as a result of changes in the benefits of these two strategies as the availability of sites for web building diminishes from early to later in the evening.

\section{Material and Methods}

Study Site

Spiders were studied at Fazenda Aretuzina $\left(21^{\circ} 26.4329^{\prime}\right.$ S, $047^{\circ} 34.9109^{\prime} \mathrm{W}$ ), near the town of São Simão in the state of São Paulo, Brazil. A total of six colonies were observed in January 2004 and 2006 and February 2005 (table B1; tables B1-B4 are available online).

\section{Dynamics of Web Building}

To determine the dynamics of web building at the start of the breakup of the bivouac, when about 40 spiders had emerged, we counted how many spiders during each 5min time period, from a sample of 40 spiders located in the central area of the scaffolding, were (1) walking along scaffolding, (2) starting to build their own web (building the radii), (3) completing web building (building the web spiral), (4) sitting in the center of a completed orb web, or (5) webless and located in the periphery of another spider's web. This procedure was continued for $1 \mathrm{~h}$, at which point web building had ceased. Subsequently, we recorded the total number of spiders present throughout the scaffolding and what percentage remained without their own web.

\section{Agonistic Behavior during Web Building and after the Completion of the Web}

To monitor agonistic behaviors during web building, we counted, in 5-min intervals, the total number of times that walking spiders were bounced at by web owners. We also recorded whether this resulted in the intruder leaving (i.e., the cases in which both spiders appeared to play the bourgeois strategy, in which the resident wins and the intruder leaves; Maynard Smith 1976, 1982) and in what percentage of cases the intruder did not retreat or managed to displace the resident and so did not appear to adhere to bourgeois roles. This procedure was repeated for a $30-\mathrm{min}$ observation period about $1 \mathrm{~h}$ after web building was complete. We predicted that bourgeois behavior would be more frequent during the web-building phase, because the cost of moving on is very low if a spider has a high probability of finding a vacant location to build its own web farther down the scaffolding. However, as potential web-building locations become occupied, it should become more profitable to become a satellite near an existing web in the hope of getting a share of the prey (see the model in app. A). To determine whether there were any asymmetries in fighting potential between the spiders with and those without a web, samples of each type (web owners and satellites) were sexed and weighed.

\section{Benefits Obtained by Webless Spiders}

To test the hypothesis that those spiders that remained webless were freeloading on spiders with a web, we measured the proportion of cases in which webless spiders (and also any neighboring residents) obtained a share of a prey item introduced into the web of a nearby web owner. We used moths and beetles, previously caught with a nearby UV light trap, as prey items.

\section{Results \\ Description of the Six Study Colonies}

The colonies contained an estimated mean of 259 spiders ( $\mathrm{SD}=148$; range: $85-450)$ and had webs with a mean extent of $10.3 \mathrm{~m}$ ( $\mathrm{SD}=5.9 \mathrm{~m}$; range: $4-20 \mathrm{~m}$; table $\mathrm{B} 1)$. The maximum height of the scaffolding (fig. 1a) extended, on average, $3.1 \mathrm{~m}$ above the ground $(\mathrm{SD}=1.7 \mathrm{~m}$; range: $1.2-5.5 \mathrm{~m}$ ). Colonies contained an average of three main 

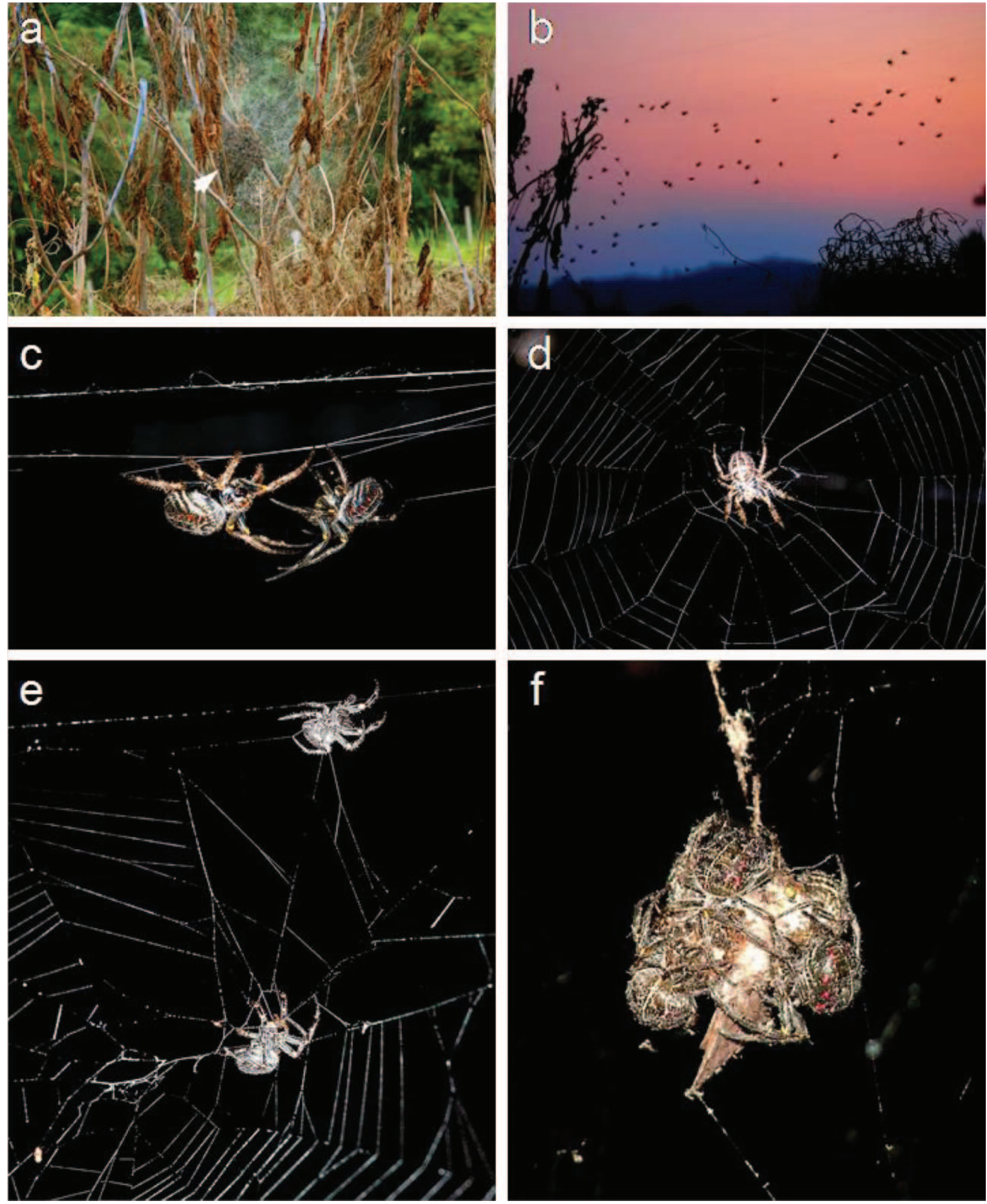

Figure 1: Typical behaviors of Parawixia bistriata. $a$, The spiders' daytime retreat or bivouac (white arrow). $b$, Spiders leaving the bivouac en masse after sunset. $c$, Two spiders passing each other, without any aggressive interaction, while depositing silk on the main support lines before initiating web building. $d$, A spider that has just completed her web. $e$, A webless spider (top) is being bounced at by a web owner (bottom). $f$, A prey item is shared between a web owner, a spider from a neighboring web, and a webless spider that had been at the edge of the web. 
sections of scaffolding silk ( $\mathrm{SD}=1.6$; range: $1-5$ ), which consisted of thick, communally built silk support lines (mean no. of lines $=17 ; \mathrm{SD}=14$; range: $8-44$ ) that connected the bivouac with nearby bushes. At night, spiders attached their individual orb webs to these support lines to create a highly effective prey-capture sheet of adjacent orb webs. An illustration of one of the study colonies is shown in figure 2. Every time a spider walked along a piece of scaffolding silk, it added another strand. As a result, over many months and with hundreds of individual movements along each piece, the scaffolding silk lines became very strong and thick, up to about $0.5 \mathrm{~mm}$ in diameter. On returning to the bivouac, each spider would first eat its web, but did not eat the scaffolding silk; the scaffolding lines are thus a permanent structure, but the orb webs within them last only 1 night.

\section{Dynamics of Web Building}

In four study colonies, the bivouac started to break up a few minutes before sunset (1955 hours), and the first spider left the bivouac 2-12 min after sunset (1957-2007 hours, mean $=5 \mathrm{~min}$ and $45 \mathrm{~s}, \mathrm{SD}=4 \mathrm{~min}$ and $21 \mathrm{~s}$ ). Spiders leave the bivouac en masse (fig. $1 b$ ); the last spider left 7-15 $\min ($ mean $=12 \min$ and $0 \mathrm{~s}, \mathrm{SD}=3 \mathrm{~min} 34$ s) after the first one left the bivouac. During this exit phase, spiders pass each other closely on the scaffolding support lines without any antagonism (fig. 1c). The construction of the whole web complex took about $1 \mathrm{~h}$ (table B2). Individual orb webs were built in about $30 \mathrm{~min}$ (fig. 1d). However, based on the counting of 40 spiders per web, an estimated $13 \%$ (SD $=8 \% ; n=4$ colonies) remained as satellites without a web (table B2), and this persisted for at least $3 \mathrm{~h}$ after web building had ceased. These webless spiders positioned themselves at the periphery of a web, with the owner at its center. Based on a count of all the spiders across six study colonies, the proportion of these satellites was lower at $6.5 \%(\mathrm{SD}=2.1 \% ; n=6$ colonies; table B1).

\section{Agonistic Behavior during and after Web Building and the Frequency of Bourgeois Behavior}

Bouncing behavior is a common response of web-owning spiders to intruders and can signal the presence of a web owner and also owner mass (Riechert 1984). We observed that, during web building by Parawixia bistriata, web owners frequently bounced at other spiders that had not yet started building their own web (table B2; fig. 1e). In 93\% of cases (189 of 203; table B2), this resulted in the intruder leaving, and in no case did the intruder take over the resident's web or engage in an escalated contest. The mean number of bounces per spider per minute correlated pos- itively with the expected encounter rate between spiders with and without a web (fig. 3; Pearson $R=0.77, P=$ .003 ) and peaked between 15 and $20 \mathrm{~min}$ after the initiation of web building. We also occasionally observed two neighboring residents bouncing at each other; in such cases, neither resident retreats, and the bouncing can be prolonged (i.e., somewhat escalated).

The frequency of bouncing significantly decreased after web building was complete (mean number of bounces per spider per minute was 0.013 [SD $=0.003$ ] during the first half hour of web building and 0.007 at $1 \mathrm{~h}$ after completion of the web $[\mathrm{SD}=0.001] ; t=4.15, \mathrm{df}=7, P=.004$; table $\mathrm{B} 3$ ). In addition, the webless satellite spiders that remained after the completion of the residents' webs appeared to play the bourgeois strategy less frequently than did wandering spiders during web establishment, with only $38(42 \%)$ of 90 leaving when bounced at by a resident. Generally, the residents stopped bouncing when their satellites became still. We observed that a small proportion of the satellites (2 [2\%] of 90$)$ actually succeeded in taking over the resident's web (table B3). This decrease in the frequency with which the webless satellite spiders appeared to play the bourgeois role was highly significant (Fisher's exact test, $P=4.10^{-26}$ ).

\section{Sex and Weight of Web Owners and Webless Spiders}

There were no significant differences in the sex ratio of the three colonies studied in 2004, and the overall ratio was not significantly different from $1: 1$ (22 [48\%] of 42 were female; binomial test: $P=.88$ ). This contrasts with the highly female-biased sex ratios in most social spiders (Avilés et al. 2006). We also observed that the sex ratio was not significantly different between web owners (14 [61\%] of 23 were female) and nearby webless spiders (8 [42\%] of 19 were female; generalized linear model [GLM] with binomial error structure, colony: Wald statistic $=$ $2.20, \mathrm{df}=2, P=.33$; web owner vs. webless spider: Wald statistic $=2.04, \mathrm{df}=1, P=.15)$. The mean weight of web owners (554 mg; SD $=152 \mathrm{mg}, n=23$ ) was not significantly different from that of nearby webless spiders (494 mg; SD $=0.106, n=19$; GLM, web owner vs. webless spider: $F=1.52, \mathrm{df}=1, P=.22$ ). Spider weights also did not differ significantly between the three colonies they were collected from in 2004 (GLM, $F=0.47$, df $=$ 2, $P=.63$ ). Hence, neither sex nor weight was correlated with whether spiders built a web; importantly, there appear to be no consistent asymmetries in fighting potential (weight) between spiders with and without a web. 


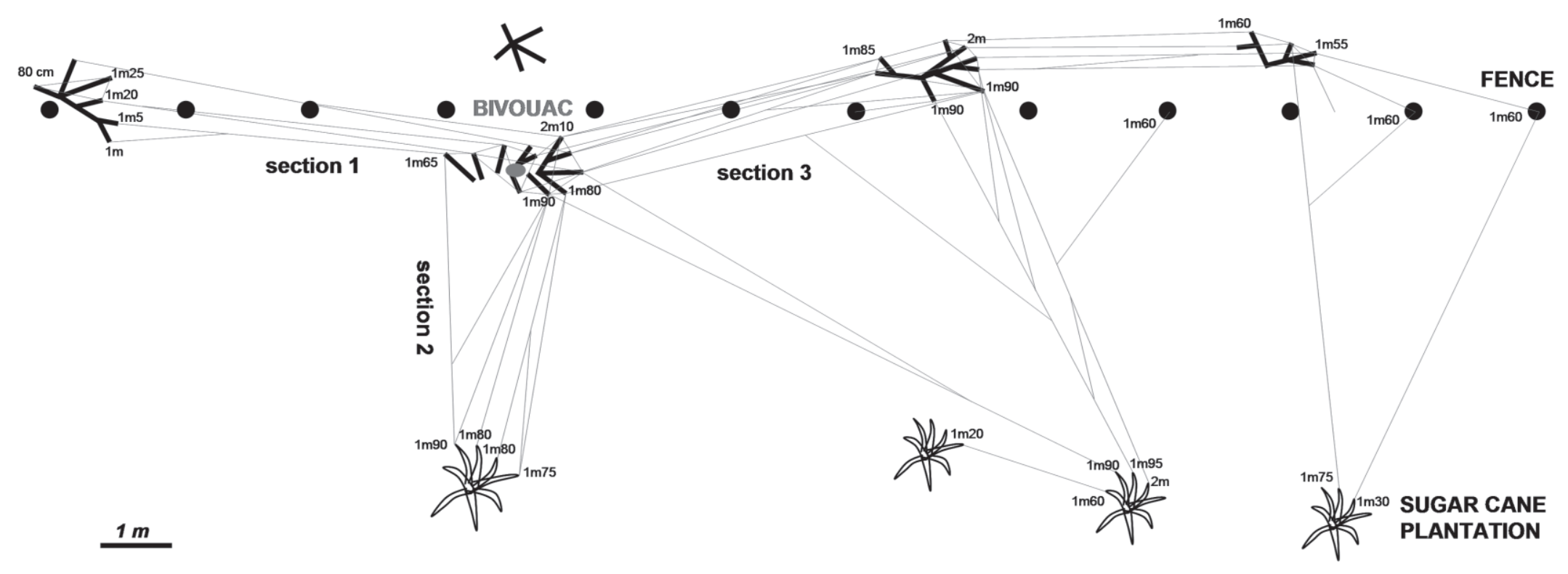

Figure 2: Plan view of study colony 2004-1 showing the position of the daytime retreat or bivouac and the main sections of thick silk support lines. The values show the height off the ground of the various attachment points, which are tree branches (thick black lines), fence posts (regular line of black circles), and sugarcane plants (in profile). 

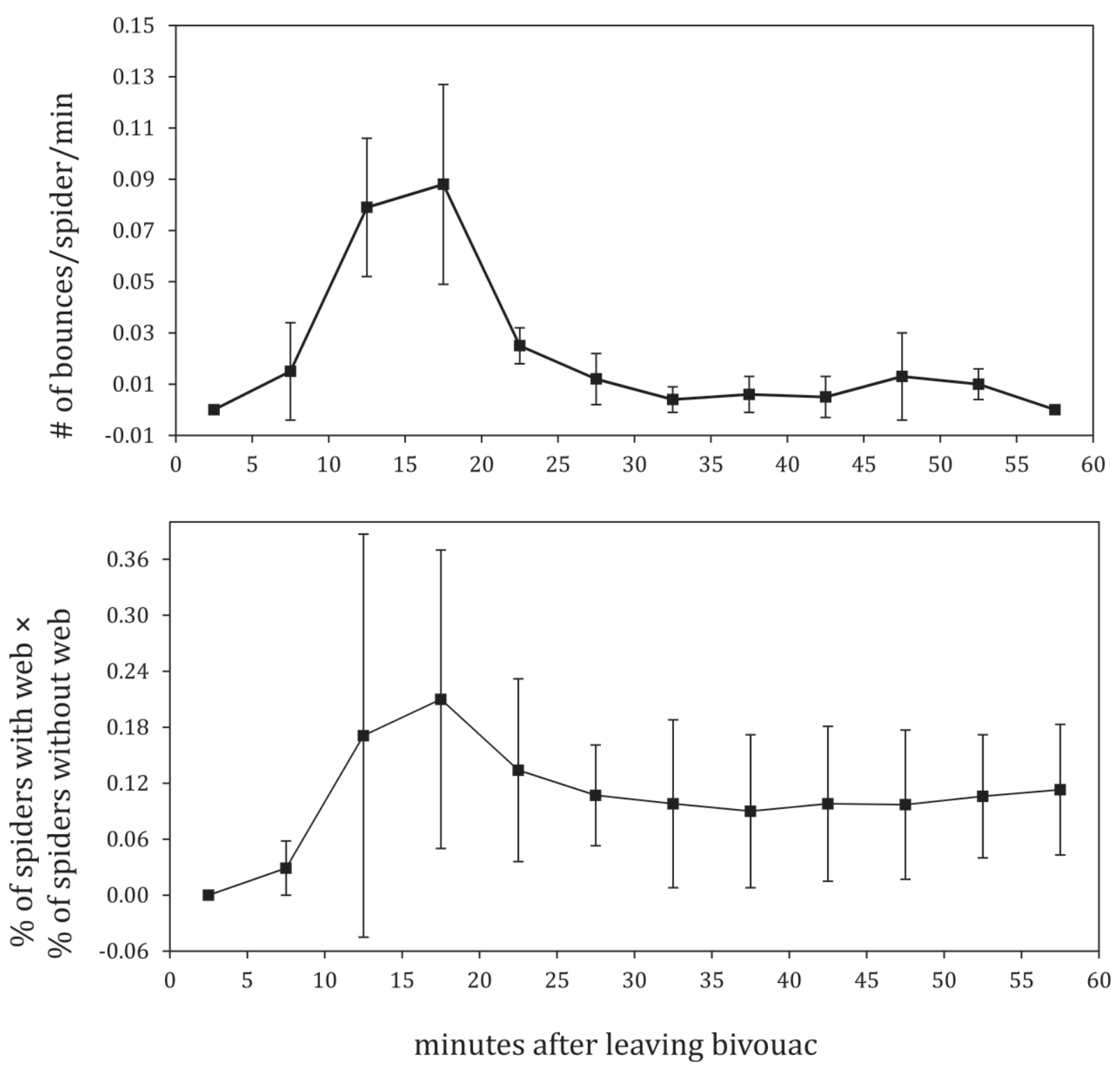

Figure 3: Bouncing behavior correlates temporally with resident/nonresident encounter frequency. Top, total mean frequency of bouncing behavior by residents to intruders during dispersal from bivouac ( $0-5 \mathrm{~min})$, web building (5-25 min), and when web building had been completed (>30 min); bottom, expected encounter rate between spiders with and those without a web. The encounter rate was calculated as the percentage of spiders with a web multiplied by the percentage of spiders without a web. Vertical bars are SDs.

\section{Benefits Obtained by Webless Spiders}

In 11 of 19 cases, one or more webless spiders obtained food when a large prey item was introduced into the web of a nearby resident. On nine occasions, the webless spider shared the prey with the resident (fig. $1 f$ ), but on two occasions, the webless spider obtained the whole prey, which it ate without sharing with the web owner (table B4). Taking into account the fact that multiple satellites were occasionally present at a web, the overall per capita probability that a webless spider obtained a share of the prey was $0.48(\mathrm{SD}=0.48)$. This shows that the satellite strategy can be successful but is less successful than being a resident.

\section{Discussion}

Our data show clearly that spiders, Parawixia bistriata, spinning their webs (the owner-residents) almost always 
successfully repel nearby walking spiders (the intruders) despite the lack of significant size differences between these two groups. One interpretation of these data is that owners of territory win over intruders as a matter of mere convention; ownership per se being respected is the hallmark of bourgeois behavior. Our second key observation is that webless spiders change their strategy once all potential web-building sites are occupied, adopting a satellite strategy, and are not repelled by the bouncing behavior of web owners.

It makes intuitive sense that the best strategy for a nonowner to follow when bounced by an owner changes from "move on" (i.e., the bourgeois strategy) when there is still a reasonable chance of finding a nearby alternative webbuilding site to "stay" as a satellite when all sites are occupied. Bourgeois behavior was first theoretically hypothesized as an "uncorrelated asymmetry" evolutionarily stable strategy (ESS) by Maynard Smith and Parker (1976) in the context of the game-theory-based hawk-dove model. We adopted the same methodology to construct a payoff matrix to formalize our verbal rationale for this change of behavioral strategy by the nonowner (see app. A).

This model supports the idea that, early in the evening, when there are still many web-building locations available that can be quickly found, intruders should move on when bounced by a resident. Later in the evening, however, when there are few vacant web-building locations that would take considerable time to find, it is better to remain at an occupied web as a satellite and to ignore the resident's bounce behaviors. In the absence of any numerical data to insert into the payoff matrix, we cannot conclude definitively that webless spiders must change their strategy from bourgeois to satellite as potential web sites become increasingly occupied. However, our formulation (app. A) does show that the argument is reasonable given the likely relative magnitudes of the various parameters.

Because the spiders in a bivouac are at the same developmental instar (Fowler and Gobbi 1988b) and are therefore evenly matched in size, they are probably evenly matched in fighting ability. As such, it is not in the interests of a resident to fight an intruder or satellite. Parawixia bistriata is univoltine; spiders grow in size over 10 months of the year (Fowler and Diehl 1978) and no doubt build webs on many days to do this. As such, the benefit of a single night's enhanced feeding through being an owner versus a satellite will be significantly lower than the risk of death through engaging in an escalated contest for sole ownership of a web.

Cooperative prey capture in $P$. bistriata seems predicated on colony members being of similar size, with synchronous development probably being mediated by chemical signaling when the spiders are in close proximity in the bivouac (Fowler and Gobbi 1988b). Size matters; single spiders taken from one colony, marked, and then introduced into another colony of spiders at the same developmental stage are accepted (J. P. Bacon and F. L. W. Ratnieks, unpublished data), but attempts to create a mixed colony of fourth- and sixth-instar spiders proved unstable, because the smaller spiders moved out of the colony (Fowler and Gobbi 1988a).

In other spider species, size asymmetries usually settle contests and override any ownership biases. Examples are found in the colonial spiders Metabus gravidus (Buskirk 1975), Metepeira atascadero and Metepeira incrassata (Hodge and Uetz 1995), and the solitary desert spider Agelenopsis aperta (Riechert 1978a, 1978b, 1979), but see the counterexample in the orb web spider Nephilengys malabarensis (Kralj-Fišer et al. 2011). The findings of this article describe less damaging outcomes of interactions between equally sized antagonists in the colonial orb web spider P. bistriata and seem to present a clear example of bourgeois behavior as a mechanism to avoid costly fighting.

The textbook example of bourgeois behavior is provided by experiments on the speckled wood butterfly Pararge aegeria; male residents of sunspots in their woodland habitat almost invariably repel potential male intruders, but experimentally displaced owners were unable to reestablish ownership after a new male had established itself in the sunspot (Davies 1978). This classic study has stimulated much useful debate and further experimentation. Significantly, some highly controlled experiments simulating the natural environment have come to a different conclusion (Kemp and Wiklund 2004); displaced male residents of sunspots are indeed able to reestablish ownership, perhaps as a result of their intrinsically more aggressive personalities, which had allowed them to claim sunspots in the first place, and possibly also the self-reinforcing effects of previous successful duels with other males (Kemp and Wiklund 2004). These sunspots are worth defending; a recent study has demonstrated that male residents of sunspots enjoy approximately twice the mating success of males confined to patrolling the shady periphery, perhaps because of the fact that females become highly conspicuous when they fly through the light beams that generate sunspots (Bergman et al. 2007).

Therefore, the speckled wood butterfly does not provide a clear example of bourgeois behavior in the sense hypothesized by Maynard Smith and Parker (1976), in which ownership is referred to as an "uncorrelated" asymmetry, because it is not logically related to success in fighting or payoff. Indeed, some researchers have questioned whether arbitrary or convention settlement of contests will ever be found in any animal species (e.g., Kemp and Wiklund 2004). However, Maynard Smith and Harper (2003) have discussed some possible examples of bourgeois behavior, 
such as the work of Gosling and McKay (1990) on house mice. Although Gosling and McKay did not discuss their data explicitly in terms of game-theory-inspired bourgeois behavior, they did, with very carefully controlled experiments, demonstrate that intruders in scent-marked areas were less likely to behave aggressively to the resident if the scent of the territory matched that of the resident. In other words, ownership, rather than the owner, was being respected.

A priori, the key experimental test after observing any pair of conspecific animals engaging, prima facie, in bourgeois behavior is to swap the locations of those animals, at which point the new owner must win subsequent confrontations. Swapping resident and nonresident $P$. bistriata would be impossible without damaging their webs, and so only indirect circumstantial evidence for bourgeois behavior can be gathered for this species. Each night, the spiders perform a natural experiment as they spin their individual orbs or assume a satellite role. By marking each spider in the colony as an individual, it might be possible to determine whether the same subset of spiders tends to be resident each night, which would suggest that stronger spiders could barge ahead and find spaces to build webs and would be better able to repel intruders; this would therefore not be true bourgeois behavior. Alternatively, observations that web ownership is randomly assigned in the population each night and is independent of the previous feeding history of each individual would be the hallmarks of authentic bourgeois behavior.

\section{Acknowledgments}

We thank V. Imperatriz-Fonseca for her help with collecting preliminary data in 2002 and D. Harper for his comments on the manuscript.

\section{APPENDIX A}

\section{Model of Decision Making by Non-Web Owners in Parawixia bistriata}

This model (tables A1-A4) investigates the payoffs of alternative strategies available to spiders that do not own a web and how this changes from early in the evening, when spiders are leaving the bivouac and many web-building locations are available, to later in the evening, when few locations are available and some spiders become satellites. From the matrix in table A4, it is clear that fighting is the worst strategy both in the early evening and later in the evening, because the payoff for fighting is negative as $c>v$ and $r>0$. Conversely, the payoffs for moving or staying are both positive, because both residents and satellites have a nonzero chance of obtaining food. The chance of being able to find a web-building location diminishes from early to late, and the time taken to find a location increases over this same period. Given that $v-c<0, r>0, v \gg w, v>s, p_{e}>p_{l}, t_{e}<t_{l}$, and $T<1$, the following series of inequalities can easily be true.

$$
\begin{aligned}
v-w> & (v-w) p_{e}\left(1-t_{e}\right)+s\left(1-p_{e}\right)\left(1-t_{e}\right)>s>(v-w) p_{l}\left(T-t_{l}\right) \\
& +s\left(1-p_{l}\right)\left(T-t_{l}\right)>0>(v / 2)(1-r) T-c(1+r) .
\end{aligned}
$$

Reading the inequalities from left to right shows that the best strategy is to own a web, as $v-w>(v-w) p_{e}(1-$ $\left.t_{e}\right)+s\left(1-p_{e}\right)\left(1-t_{e}\right)$. That is, the best strategy is to establish a web if a suitable vacant location is found when dispersing from the bivouac. Early in the evening, when webs are being initiated but many locations are still available, the best strategy for a nonresident that is bounced by a resident is to move on and seek a vacant location, given that $(v-$ $w) p_{e}\left(1-t_{e}\right)+s\left(1-p_{e}\right)\left(1-t_{e}\right)>s$ (i.e., $p_{\mathrm{e}}$ close to $1, t_{\mathrm{e}}$ close to 0$)$. But later on, when webs have been established and there are few or zero web-building locations available, it is better to stay as a satellite even when bounced, because $s>(v-w) p_{l}\left(T-t_{l}\right)+s\left(1-p_{l}\right)\left(T-t_{l}\right)$ (i.e., $\left.0<p_{l}<<1,0<T-t_{l}<<1\right)$. Finally, $s\left(1-p_{l}\right)\left(T-t_{l}\right)>0>(v / 2)(1-$ $r) T-c(1+r)$ shows that it is not worth fighting even late in the evening, because the cost of fighting is always greater than the value of web ownership for 1 night. Increasing relatedness among spiders increases overall cost of fighting.

Table A1: Strategy set of intruder when beside an owned web

\begin{tabular}{ll}
\hline Strategy & \multicolumn{1}{c}{ Action } \\
\hline Move & Intruder moves on when resident makes the bounce behavior \\
Stay & Intruder stays at edge of web as a satellite when bounced by the owner \\
Fight & Intruder fights web owner for web ownership \\
\hline
\end{tabular}


Table A2: Model parameters

\begin{tabular}{ll}
\hline Variable & Description \\
\hline$v$ & $\begin{array}{c}\text { Value of owning a web for } 1 \text { night (i.e., food collected as owner translated into fit- } \\
\text { ness terms) } \\
s\end{array}$ \\
& $\begin{array}{c}\text { Value of being a satellite for } 1 \text { night (i.e., food collected as satellite spider who } \\
\text { remains at the edge of an owner's web and eats the owner's surplus food trans- }\end{array}$ \\
& lated into fitness terms) \\
$p_{e} p_{l}$ & Probabilities of finding a web-building location early or late in the evening \\
$t_{e} t_{l}$ & Time taken to locate a vacant web-building location early or late \\
$T$ & Proportion of time remaining later in the evening \\
$c$ & Cost of fighting to owner or intruder \\
$w$ & Cost of building a web \\
$r$ & Relatedness among spiders
\end{tabular}

Table A3: Starting assumptions and rationales

\begin{tabular}{|c|c|}
\hline Assumption & Rationale \\
\hline$v>s$ & Residents obtain more food than satellites, on average \\
\hline$s>0$ & Satellites sometimes can feed, such as by sharing large prey items \\
\hline$p_{e}>p_{l}$ & $\begin{array}{l}\text { Probability of finding a vacant web-building location diminishes greatly from early } \\
\text { to late evening; probably } p_{e} \gg p_{l}\end{array}$ \\
\hline$t_{e}<t_{l}$ & $\begin{array}{l}\text { Time taken to find a web-building location increases from early to late evening; } \\
\text { probably } t_{e} \ll t_{l} \text { and } t_{\mathrm{e}} \text { small (i.e., early in the evening, a location is found } \\
\text { quickly) }\end{array}$ \\
\hline$T<1$ & A web established later in the evening will catch less prey \\
\hline$c>v$ & $\begin{array}{l}\text { Fitness cost of fighting, the risk of death or injury, is greater than the fitness benefit } \\
\text { of web owning, given that web ownership only lasts } 1 \text { night, whereas feeding and } \\
\text { web building opportunities will occur on many nights throughout a spider's life }\end{array}$ \\
\hline$w \ll v$ & $\begin{array}{l}\text { Cost of building a web is low relative to the value of a web, given that a spider eats } \\
\text { its own web at the end of the night and web mass is small }\end{array}$ \\
\hline
\end{tabular}

Table A4: Payoff matrix

\begin{tabular}{lll}
\hline Strategy & \multicolumn{1}{c}{ Early evening } & \multicolumn{1}{c}{ Late evening } \\
\hline Move & $(v-w) p_{e}\left(1-t_{e}\right)+s\left(1-p_{e}\right)\left(1-t_{e}\right)$ & $(v-w) p_{l}\left(T-t_{l}\right)+s\left(1-p_{l}\right)\left(T-t_{l}\right)$ \\
Stay & $s$ & $s T$ \\
Fight $^{\text {a }}$ & $(v / 2)(1-r)-c(1+r)$ & $(v / 2)(1-r) T-c(1+r)$
\end{tabular}

a The payoffs in these two cells include both direct and indirect fitness components. In early evening, the term $(v / 2)(1-r)$ is $v / 2$ (benefit of winning with chance $50 \%)$ minus $r v / 2$, the loss to the opponent from not winning times relatedness. In early evening, the term $c(1+r)$ is the direct cost of fighting, $c$, plus the cost to the opponent times relatedness, $c \times r$. In this model, a fighting cost is paid by both winner and loser. Later in the evening, the benefit of winning is discounted, $T$, but the cost is not discounted. When relatedness is zero, the early evening payoff is $v / 2-c$.

\section{Literature Cited}

Avilés, L. 1997. Causes and consequences of cooperation and permanent-sociality in spiders. Pages 476-498 in J. C. Choe and B. Crespi, eds. The evolution of social behavior in insects and arachnids. Cambridge University Press, Cambridge.
Avilés, L., W. P. Maddison, and I. Agnarsson. 2006. A new independently derived social spider with explosive colony proliferation and a female size dimorphism. Biotropica 38:743-753.

Azara, F. D. 1809. Pages 212-213 in Voyages dans l'Amérique Méridionale par don Felix de Azara de 1781 a 1801. Vol. 1. Dentu, Paris. Bergman, M., K. Gotthard, D. Berger, M. Olofsson, D. J. Kemp, and 
C. Wiklund. 2007. Mating success of resident versus non-resident males in a territorial butterfly. Proceedings of the Royal Society B: Biological Sciences 274:1659-1665.

Buskirk, R. E. 1975. Aggressive display and orb defence in a colonial spider, Metabus gravidus. Animal Behaviour 23:560-567.

Campon, F. F. 2007. Group foraging in the colonial spider Parawixia bistriata (Araneidae): effect of resource levels and prey size. Animal Behaviour 74:1551-1562.

Davies, N. B. 1978. Territorial defence in the speckled wood butterfly (Pararge aegeria): resident always wins. Animal Behaviour 26:138147.

Darwin, C. 1845. Pages 59 and 130 in Journal of researches into the natural history and the geology of the countries visited during the voyage of H.M.S. Beagle round the world. J. Murray, London.

Fowler, H. G., and J. Diehl. 1978. Biology of a Paraguayan colonial orb-weaver Eriophora bistriata (Rengger) (Araneae, Araneidae). Bulletin of the British Arachnological Society 4:241-250.

Fowler, H. G., and N. Gobbi. 1988a. Cooperative prey capture by an orb-web spider. Naturwissenschaften 75:208-209.

- 1988b. Communication and synchronized molting in a colonial araneid spider, Eriophora bistriata. Experientia 44:720-722.

Gobbi, N., R. Zucchi, and S. F. Sakagami. 1979. General behavioral patterns and life-cycle of the colonial spider Eriophora bistriata (Araneidae, Argiopidae). Boletim de Zoologia (Universidade de São Paulo) 4:65-74.

Gosling, L. M., and H. V. McKay. 1990. Competitor assessment by scent matching: an experimental test. Behavioural Ecology and Sociobiology 26:415-420.

Hodge, M. A., and G. W. Uetz. 1995. A comparison of agonistic behaviour of colonial web-building spiders from desert and tropical habitats. Animal Behaviour 50:963-972.

Kemp, D. J., and C. Wiklund. 2004. Residency effects in animal contests. Proceedings of the Royal Society B: Biological Sciences 271:1707-1711.

Kralj-Fišer, S., M. Gregoric, S. C. Zhang, D. Q. LI, and M. Kuntner. 2011. Eunuchs are better fighters. Animal Behaviour 81:933-939.

Levi, H. W. 1992. Spiders of the orb-weaver genus Parawixia in America (Araneae: Araneidae). Bulletin of the Museum of Comparative Zoology at Harvard College 153:1-46.

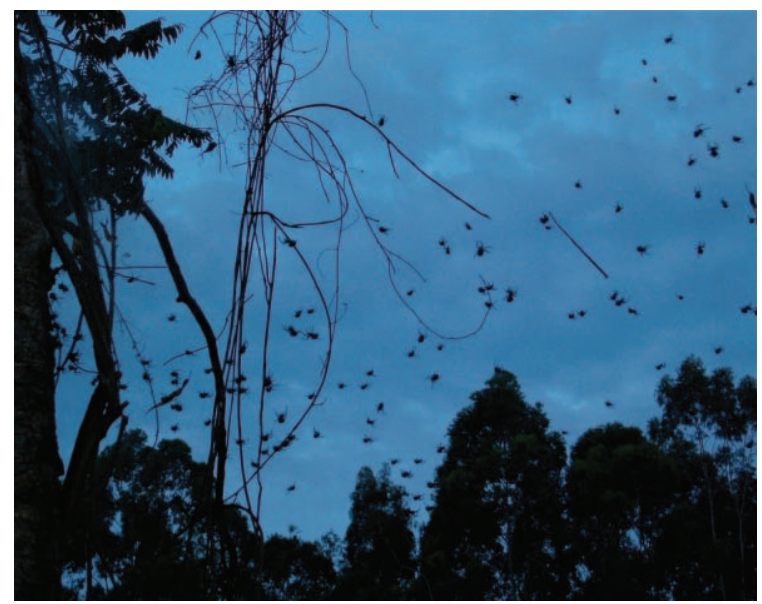

Maynard Smith, J. 1976. Evolution and the theory of games. American Scientist 64:41-45.

. 1982. Evolution and the theory of games. Cambridge University Press, New York.

Maynard Smith, J., and D. G. C. Harper. 2003. Page 57 in Animal signals. Oxford University Press, Oxford.

Maynard Smith, J., and G. A. Parker. 1976. The logic of asymmetric contests. Animal Behaviour 24:159-175.

Mesterton-Gibbons, M. 1992. Ectopic variation in the asymmetric hawk-dove game: when is bourgeois an evolutionary stable strategy? Evolutionary Ecology 6:198-222.

Quintero, J. H., and G. Amat. 1996. Un caso de sociabilidad en arenas (Araneae: Nesticidae) del Parque Amacayacu, Amazonas. Universitas Scientarum 2:51-62.

Riechert, S. E. 1978a. Energy-based territoriality in populations of the desert spider Agelenopsis aperta (Gertsch). Symposia of the Zoological Society of London 42:211-222.

. 1978b. Games spiders play: behavioral variability in territorial disputes. Behavioral Ecology and Sociobiology 3:135-162.

1979. Games spiders play: II. Resource assessment strategies. Behavioral Ecology and Sociobiology 6:121-128.

- 1984. Games spiders play: III. Cues underlying contextassociated changes in agonistic behaviour. Animal Behaviour 32: $1-15$.

Sandoval, C. P. 1987. Aspectos da ecologia e socialidade de uma aranha colonial: Eriophora bistriata (Rengger 1936) (Araneidae). Universidad Estadual de Campinas, Brazil.

Uetz, G. W., and C. S. Hiebe. 1997. Colonial web-building spiders: balancing the costs and benefits of group-living. Pages 458-475 in J. C. Choe and B. J. Crespi, eds. The evolution of social behavior in insects and arachnids. Cambridge University, Cambridge.

Vollrath, F. 1986. Eusociality and extraordinary sex-ratios in the spider Anelosimus eximius (Araneae, Theridiidae). Behavioral Ecology and Sociobiology 18:283-287.

Associate Editor: Andy Gardner Editor: Troy Day

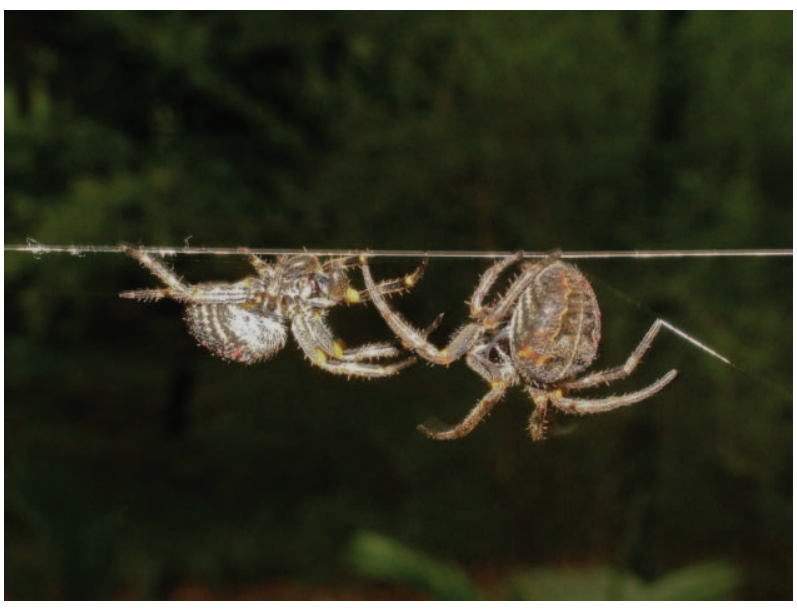

Left, spiders emerging early in the evening seemingly suspended against the night sky. Right, a pair of spiders passing each other, without any aggression, on a thick silk line. Photograph by F. L. W. Ratnieks. 